\title{
CONTRIBUIÇÃO DA CERTIFICAÇÃO FLORESTAL AO ATENDIMENTO DA LEGISLAÇÃO AMBIENTAL E SOCIAL NO ESTADO DE MINAS GERAIS ${ }^{1}$
}

\author{
Vanessa Maria Basso², Laércio Antônio Gonçalves Jacovine ${ }^{3}$, Ricardo Ribeiro Alves ${ }^{4}$ e Áurea Maria \\ Brandi Nardelli ${ }^{5}$
}

\begin{abstract}
RESUMO - Nas últimas décadas, a maior preocupação ambiental vem tendo reflexos em vários setores da economia e na maneira como os produtos são avaliados pelos consumidores. Especificamente com relação aos produtos florestais, o mercado passou a exigir garantias de que estes não sejam oriundos de atividades ilegais. Um dos instrumentos desenvolvidos para tal fim foi a certificação florestal, representada atualmente no Brasil pelos sistemas Forest Stewardship Council (FSC) e CERFLOR/PEFC. A certificação, além de atestar o sistema de manejo da operação florestal, exige o cumprimento das legislações nacionais vigentes no país. O Brasil, apesar de possuir legislação ambiental e trabalhista bastante completa, apresenta, de forma geral, dificuldade em seu efetivo cumprimento. Nas organizações florestais, o quadro não é diferente, pois as questões legais foram um dos principais desvios verificados nos relatórios de certificação. Assim, este trabalho teve por objetivo verificar a contribuição da certificação florestal no Estado de Minas Gerais no que diz respeito a aspectos de conformidade com a legislação ambiental e social. Para isso, buscaram-se os dados nos relatórios públicos das unidades de manejo florestal certificadas pelo FSC até dezembro de 2008. A análise teve foco em dois dos 10 princípios do FSC: Princípio 1 "Obediência às leis a aos princípios e critérios do FSC" e Princípio 4 "Relações comunitárias e direitos dos trabalhadores", que estão diretamente ligados ao atendimento das questões ambientais e sociais. Os resultados indicaram que o principal problema no âmbito legal foi o descumprimento da legislação ambiental, especificamente relacionado às áreas de preservação permanente e reserva legal. Já as questões sociais mais relatadas se referem aos requisitos de saúde e segurança do trabalho, em especial à Norma Regulamentadora NR -31. Para que se obtenha e mantenha o certificado de manejo, é exigido que todas as não conformidades sejam tratadas no sentido de serem corrigidas. Dessa forma, concluiuse que a certificação florestal é um mecanismo que efetivamente contribui para o cumprimento da legislação ambiental e social do setor florestal no Estado de Minas Gerais.
\end{abstract}

Palavras-chave: FSC, Manejo florestal e Plantações florestais.

\section{CONTRIBUTION OF FOREST CERTIFICATION IN THE ATTENDANCE TO THE ENVIRONMENTAL AND SOCIAL LEGISLATION IN MINAS GERAIS STATE}

\begin{abstract}
In the last decades, the greatest environmental preoccupation is having a repercussion in several sectors of the economy and how the products are being evaluated by the consumers. Specifically to forest products, the market began to require guarantees that they weren't derived from illegal activities. One of the instruments developed for this purpose was the forest certification, represented in Brazil by the FSC (Forest Stewardship Council) and CERFLOR systems. This certification, besides attesting the system offorest management operation also requires compliance with the laws prevailing in the country. Brazil, despite having an environmental
\end{abstract}

\footnotetext{
${ }^{1}$ Recebido em 06.07.2010 e aceito para publicação em 28.05.2012.

${ }^{2}$ Programa de Pós-Graduação em Ciência Florestal, Universidade Federal de Viçosa, UFV, Brasil. E-mail: vanessa.basso@ ufv.br

${ }^{3}$ Universidade Federal de Viçosa, Departamento de Engenharia Florestal. E-mail: <jacovine@ufv.br>.

${ }^{4}$ Universidade Federal do Pampa, Campus São Gabriel (RS). E-mail: <ricardoalves@ unipampa.edu.br>.

${ }^{5}$ Doutora em Ciência Florestal. E-email: <aurea.nardelli@terra.com.br>.
} 
having an environmental and labor legislation fairly complete has, in general, difficulty in their effective enforcement. In forestry organizations, the picture is not different because the legal issues were one of the main differences in the certification reports. The present study aimed to verify the contribution offorest certification in Minas Gerais state with regard to aspects of conformity to environmental and social legislation. For this, were sought the data in the public reports of the management units certified by FSC until December 2008. The analysis had focus on two of the ten FSC principles: Principle 1 - "Compliance with laws and FSC principles and criteria" and principle 4 "Community relations and workers rights". The results indicated that the principal problem in the legal ambit was the noncompliance of environmental legislation, specifically related to permanent preservation areas and legal reserve. Already the most reported social questions refer to the requirements of health and safety of work, in special to the regulatory norm NR-31. To obtain and keep the management certificate is required that all the nonconformities are treated in order to be corrected. Thus, was concluded that forest certification is a mechanism that effectively contributes to the compliance of environmental and social legislation in forest sector in Minas Gerais state.

Keywords: FSC, Forest management and Forest plantations.

\section{INTRODUÇÃO}

O setor florestal no Brasil representa mais de 3,4\% do PIB nacional (SBS, 2008). Dados da Associação Brasileira de Produtores de Florestas Plantadas (ABRAF, 2009) indicaram que somente a silvicultura, ou seja, as plantações florestais, gerou em 2008 um total de 8,82 bilhões de reais em arrecadações de tributos, e seu valor bruto de produção chegou a 52,8 bilhões de reais e contribuiu com aproximadamente 4,7 milhões de postos de trabalho (diretos e indiretos) em todo o país.

Há no país mais de seis milhões de hectares de plantações florestais, quase que exclusivamente dos gêneros Eucaliptus e Pinus. A maior parte dessas plantações está concentrada nas Regiões Sul e Sudeste, tendendo a se expandir por todo o território nacional e a diversificar as espécies plantadas, devido à crescente demanda de madeira e seus derivados.

O Estado de Minas Gerais apresenta a maior área de florestas plantadas do país, perfazendo um total de mais um milhão e meio de hectares (ABRAF, 2011). Segundo dados da Associação Mineira de Silvicultura (AMS, 2011), o setor florestal representa cerca de 7\% do PIB estadual, agregando mais de três bilhões de reais em exportações e respondendo pela geração de 746 mil empregos.

Em Minas Gerais, a cadeia produtiva decorrente da utilização das florestas plantadas abrange o parque siderúrgico mineiro de produção de ferro-gusa a carvão vegetal, a indústria de celulose branqueada, a indústria de painéis de madeira, a produção de madeira serrada e de produtos sólidos de madeira, além de um crescente parque moveleiro, o qual possui 1.650 empreendimentos instalados (VIEIRA, 2006). Entretanto, juntamente com o crescimento da produção florestal, tem surgido maior preocupação com os aspectos e impactos ambientais e sociais dessas atividades. Essa preocupação está sendo impulsionada pela repercussão de notícias a respeito da destruição de florestas tropicais e os consequentes efeitos sobre o clima global.

Segundo Alves et al. (2009), a discussão em torno das questões ambientais e suas relações com o setor florestal são bem nítidas, principalmente em razão da contínua redução das áreas ocupadas por florestas nativas em várias partes do planeta. O boicote a produtos florestais foi uma das estratégias adotadas por ambientalistas para comunicar ao setor a necessidade de mudanças. Contudo, o simples boicote não é uma medida eficaz para promover as mudanças necessárias. Um mecanismo de mercado, que permitisse rotular produtos originados de florestas bem manejadas e com isso premiasse ou reconhecesse os produtores, surgiu como alternativa a ser implementada em respostas aos boicotes. Sistemas de avaliação independente e de certificação voluntária do manejo florestal foram criados em vários países, e um deles foi o Forest Stewardship Council (FSC). Fundado em 1993, o FSC é hoje, juntamente com o Programme for Endorsement of Forest Certification Schemes (PEFC) (representado no Brasil pelo programa Cerflor), um dos mais importantes sistemas de certificação em escala global. O objetivo dos sistemas de certificação é promover o "bom manejo" das florestas, por meio de práticas ambientalmente corretas, socialmente benéficas e economicamente viáveis.

Revista Árvore, Viçosa-MG, v.36, n.4, p.747-757, 2012 
O chamado "bom manejo" é quando as atividades florestais são realizadas de acordo com um plano de manejo, em que as questões ambientais e sociais são incorporadas por meio da minimização dos impactos negativos e potencialização dos positivos.

Ao buscar uma certificação, as empresas estão lançando mão de um instrumento institucionalizado de diferenciação, com o objetivo de informar e garantir ao consumidor e às demais partes interessadas que determinados padrões de desempenho de seu manejo florestal estão sendo atingidos e monitorados (NARDELLI; GRIFFITH, 2003).

Em termos de área no Brasil, a certificação de manejo florestal do FSC abrange 4.720.645 ha de florestas certificadas, sendo 497.020, 60 ha no Estado de Minas Gerais (FSC, 2010). Acertificação Cerflor possui 1.170.136ha de florestas certificadas no Brasil, sendo 335.778 ha em Minas (INMETRO, 2010). Assim, verifica-se que o sistema FSC é o mais utlizado no Brasil e em Minas Gerais.

O padrão FSC é composto por 10 princípios, que procuram verificar se todas as áreas de atuação do manejo florestal (social, ambiental, legal e econômica) estão de acordo com os padrões de desempenho estabelecidos.

Entre esses princípios, o primeiro e o quarto estão diretamente ligados ao atendimento das questões ambientais legalmente exigidas e às questões sociais, sendo eles: "Obediência às leis e aos princípios do FSC" e "Relações comunitárias e direitos dos trabalhadores".

Assim, buscou-se avaliar a real contribuição do sistema de certificação FSC para a melhoria de desempenho do setor florestal mineiro, no que diz respeito ao atendimento de questões de cunho legal e de questões sociais.

\section{MATERIAL E MÉTODOS}

Este estudo foi desenvolvido a partir de metodologias da pesquisa social, sendo esta caracterizada como pesquisa descritiva. Segundo Gil (2008):

As pesquisas deste tipo têm como objetivo primordial a descrição de características específicas de determinada população humana (sociais, econômicas, entre outras) ou fenômeno ou estabelecimento de relações entre variáveis. Algumas pesquisas descritivas vão além da simples identificação da existência de relações entre variáveis, pretendendo determinar a natureza dessa relação.

Este estudo procurou, dessa forma, estabelecer a relação entre a adesão ao processo de certificação florestal e o cumprimento de algumas legislações, em específico a ambiental e a trabalhista, verificando, assim, a influência da variável certificação sobre o cumprimento dessas legislações nas organizações que se submeteram a esse processo.

Como delineamento para a elaboração do trabalho, utilizou-se a pesquisa bibliográfica e documental. A parte inicial do trabalho foi composta pela pesquisa bibliográfica como fonte de informações sobre o assunto. Segundo Gil (2008), "esta é desenvolvida a partir de material já elaborado principalmente de livros e artigos científicos".

O banco de dados foi composto por meio de pesquisa documental, que, de acordo com Gil (2008), se assemelha muito à pesquisa bibliográfica, porém a exploração dos dados consiste de fontes documentais que podem ser documentos de primeira ou segunda mão. Documentos de primeira mão são aqueles que não receberam nenhum tratamento analítico, como documentos oficiais, reportagens de jornal, cartas, contratos, filmes, fotografias, entre outros. Já os documentos considerados de segunda mão são aqueles que, de alguma forma, foram analisados, como: relatórios de pesquisa, relatórios de empresas, tabelas estatísticas, entre outros.

O banco de dados foi realizado através de verificação de documentos de primeira mão, ou seja, através da verificação e análise de documentos oficiais (relatórios de auditoria principal e monitoramentos) de certificação florestal das unidades de manejo do Estado de Minas Gerais certificadas no período de 1998 a 2009, pelo sistema FSC. Esses são documentos públicos que são disponibilizados com o objetivo de dar transparência ao processo de certificação. Nesse documento são descritas as ações desenvolvidas na unidade de manejo para o atendimento de todos os princípios e critérios definidos no padrão e necessários para que se obtenha a certificação.

Os relatórios das organizações certificadas no Estado de Minas Gerais foram obtidos nas certificadoras credenciadas pelo FSC no Brasil: Programa SMART WOOD - Representante no Brasil: IMAFLORA - Instituto

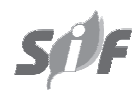

Revista Árvore, Viçosa-MG, v.36, n.4, p.747-757, 2012 
de Manejo e Certificação Florestal e Agrícola (IMAFLORA, 2008); SCS - Scientific Certification System, Inc. - Programa Forest Conservation (SCS, 2008); SGS - Société Générale de Surveillance Programa SGS (SGS, 2008), juntamente com o FSC (FSC, 2008).

No total foram verificadas, pelo sistema FSC, sete unidades de manejo florestal certificadas no Estado de Minas Gerais, perfazendo um total de 497.020,60 ha, das quais as áreas de cada uma estão listadas a seguir:

a) Organização florestal A: 122.823,62 ha

b) Organização florestal B: 27.635,79 ha

c) Organização florestal C: $118.805,75$ ha

d) Organização florestal D: 8.987,00 ha

e) Organização florestal E: $34.596,90$ ha

f) Organização florestal F: 57.908,00 ha

g) Organização florestal G: 126.263,54 ha

O padrão FSC é composto por 10 princípios, que são:

- Princípio 1: Obediência às leis e aos princípios do FSC

- Princípio 2: Direitos e responsabilidades de posse e uso

- Princípio 3: Direitos dos povos indígenas

- Princípio 4: Relações comunitárias e direitos dos trabalhadores

- Princípio 5: Benefícios da floresta

- Princípio 6: Impacto ambiental

- Princípio 7: Plano de manejo

- Princípio 8: Monitoramento e avaliação

- Princípio 9: Manutenção de florestas de alto valor de conservação

- Princípio 10: Plantações de árvores

Foram quantificadas todas as não conformidades em cada um dos 10 princípios de cada relatório verificado, porém a análise teve foco no Princípio 1, relacionado à "Obediência às leis e aos princípios e critérios do FSC" e no Princípio 4 "Relações comunitárias e direito dos Trabalhadores".

Revista Árvore, Viçosa-MG, v.36, n.4, p.747-757, 2012
No Princípio 1 foi verificado se "o manejo florestal respeitava todas as leis aplicáveis ao país onde opera, os tratados internacionais e os acordos assinados pelo país, e a obediência aos demais Princípios e Critérios do FSC". Esse princípio requer o cumprimento, por parte do empreendimento, de toda a legislação vigente no que diz respeito à atividade florestal, incluindo as legislações trabalhista, tributária, fundiária e ambiental, além de outras que sejam aplicáveis. As exigências com relação à obediência aos princípios do FSC têm como objetivo principal assegurar um compromisso de longo prazo para com o manejo dos recursos florestais, por meio da garantia de sua viabilidade econômica e socioambiental.

No Princípio 4 foi verificado se "as atividades de manejo florestal mantiveram ou ampliaram no longo prazo, o bem-estar econômico e social dos trabalhadores florestais e das comunidades locais". Nesse princípio são tratadas todas as questões ligadas aos trabalhadores, incluído o cumprimento de leis e normas trabalhistas do país, sendo também verificadas condições para a melhoria do trabalho, como: preferência por trabalhadores locais, controle para diminuição da rotatividade, treinamentos, organização sindical, verificação de queixas, entre outros. Também é exigida a avaliação dos impactos sociais aos trabalhadores e a toda a comunidade do entorno das atividades florestais.

Não conformidade é o termo utilizado para indicar que na Unidade de Manejo Florestal (UMF) estão sendo descumpridos alguns requisitos que são prescritos pelo padrão. Quando há um descumprimento destes, é aplicada à UMF uma solicitação de ação corretiva para a não conformidade identificada.

Ao ser identificada, a não conformidade também é classificada, quanto à sua gravidade, em maior ou menor, de acordo com as normas do FSC. Uma não conformidade é considerada maior se resultar em falha fundamental para atingir o objetivo do critério no qual está inserido. Não conformidade menor não compromete o atendimento do objetivo do critério e é correção necessária que a UMF deverá implementar em prazos finais específicos (curto prazo - usualmente menos de um ano). Porém, várias não conformidades menores (em um mesmo critério) poderão determinar uma não conformidade maior. Essa classificação também foi verificada na análise. 
Após a quantificação e análise, as não conformidades referentes aos Princípios 1 e 4 do padrão FSC foram separadas em categorias de acordo com a legislação pertinente ou em critérios específicos exigidos pelo padrão. Com a classificação dessas por categoria, foi possível desenvolver o estudo sobre os problemas de desempenho mais frequentes nas organizações florestais avaliadas.

\section{RESULTADOS}

Nos relatórios de certificação (auditoria principal e monitoramentos) analisados foi identificado, nas sete unidades de manejo florestal localizadas em Minas Gerais, um total de 266 não conformidades referentes aos 10 princípios do padrão FSC, e 45,8\% dessas não conformidades estavam relacionadas aos Princípios 1 e 4 (Tabela 1 ).

Na Figura 2, verifica-se também alto percentual no Princípio 6 (impacto ambiental), porém este princípio trata de questões específicas da norma que não envolvem os quesitos legais nacionais e, portanto, não foram abordados neste trabalho.

De acordo com as normas do FSC, toda não conformidade constatada é analisada e classificada quanto à sua gravidade, podendo ser maior ou menor.

Tabela 1 - Número de não conformidades encontradas nos relatórios de certificação de Minas Gerais, * considerando o total de não conformidades levantadas em todas as auditorias no período avaliado.

Table 1 -Number of nonconformities found on the certification reports of Minas Gerais, *considering the totality of nonconformities raised on all audits in the valued period.

\begin{tabular}{cccc}
\hline Princípio & $\begin{array}{c}\text { Número de Não } \\
\text { conformidades }\end{array}$ & $\%$ & $\begin{array}{c}\text { Média por unidade } \\
\text { de manejo } *\end{array}$ \\
\hline $\mathbf{1}$ & 39 & 15,3 & 5,6 \\
$\mathbf{2}$ & 5 & 1,9 & 0,7 \\
$\mathbf{3}$ & 2 & 0,8 & 0,3 \\
$\mathbf{4}$ & 91 & 35,5 & 13 \\
$\mathbf{5}$ & 10 & 3,9 & 1,4 \\
$\mathbf{6}$ & 59 & 23,1 & 8,4 \\
$\mathbf{7}$ & 9 & 3,5 & 1,3 \\
$\mathbf{8}$ & 21 & 8,2 & 3,0 \\
$\mathbf{9}$ & 9 & 3,5 & 1,3 \\
$\mathbf{1 0}$ & 11 & 4,3 & 1,6 \\
\hline Total & 256 & 100,0 & 38,0 \\
\hline
\end{tabular}

Na Tabela 2 é apresentado o total de não conformidades de acordo com sua gravidade, em que Maior significa maior gravidade $(+\mathrm{G})$ e Menor, menor gravidade (-G).

Do total das 266 não conformidades verificadas em todos os Princípios, 35 foram consideradas do tipo maior (Tabela 2). Dessas, 13 foram referentes aos Princípios 1 e 4, representando $37,1 \%$ das não conformidades maiores e $52,9 \%$ menores.

As não conformidades maiores precisam ser resolvidas antes da certificação. Dessa forma, tem-se um efeito direto e imediato no cumprimento da legislação. Já as não conformidades menores são abertas para monitoramento, ou seja, tem-se maior tempo para se resolver o problema. Assim, há apenas alguns aspectos legais, em que se pode demandar maior tempo para ser resolvido, a exemplo da adequação das áreas de preservação permanente ou da averbação das áreas de reserva legal. Dessa forma, é aceito um plano de ação com um cronograma de execução para o atendimento a essas questões, que serão monitoradas ao longo dos próximos anos.

\subsection{Princípio 1 - Obediência às leis e aos Princípios do FSC}

Após a análise das não conformidades referentes ao Princípio 1, estas foram selecionadas e agrupadas em seis categorias de acordo com o problema verificado. Observou-se que a principal demanda foi referente à legislação ambiental (Figura 1), com um total de 61\%, seguida pela legislação trabalhista $(12 \%)$ e legislação em geral $(12 \%)$.

O item de legislações em geral contemplou as não conformidades que abordavam temas referentes à legislação nacional como um todo. Em suma, todas

Tabela 2 - Total de não conformidades classificadas de acordo com a gravidade.

Table 2 - Total of nonconformities classified according to the severity.

\begin{tabular}{lcccc}
\hline & $\mathrm{G}+$ & $\%$ & $\mathrm{G}-$ & $\%$ \\
\hline Princípio 1 & 2 & 5,7 & 37 & 16,7 \\
Princípio 4 & 11 & 31,4 & 80 & 36,2 \\
Subtotal & 13 & 37,1 & 117 & 52,9 \\
Outros princípios & & & & \\
$(2,3,5,6,7,8,9$ e 10) & 22 & 62,9 & 104 & 47,1 \\
\hline Total & 35 & 100 & 221 & 100 \\
\hline
\end{tabular}

Revista Árvore, Viçosa-MG, v.36, n.4, p.747-757, 2012 
essas não conformidades tratavam da reciclagem de seus trabalhadores quanto às legislações, necessidade de treinamentos, principalmente em nível gerencial.

Os principais problemas referentes à legislação ambiental foram com relação à averbação das áreas de reserva legal (RL) e manutenção das áreas de preservação permanente (APPs), que somados representaram $50 \%$ do total.

Os problemas referentes às APPs estavam relacionados à falta de mapeamento e comprovação em campo da existência dessas áreas, ou seja, estas

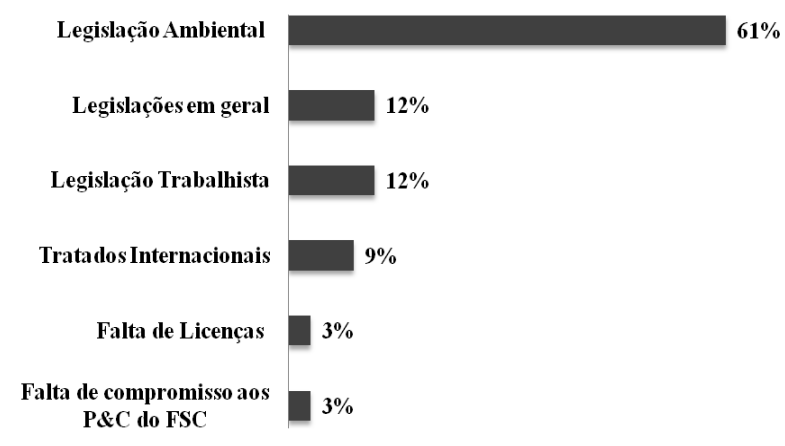

Figura 1 - Percentual de não conformidades por categoria referentes ao Princípio 1, nas Unidades de Manejo Florestal do Estado de Minas Gerais.

Figure 1-Percentage of nonconformities by category referents to Principle 1, in the Forest Management Units of Minas Gerais state.

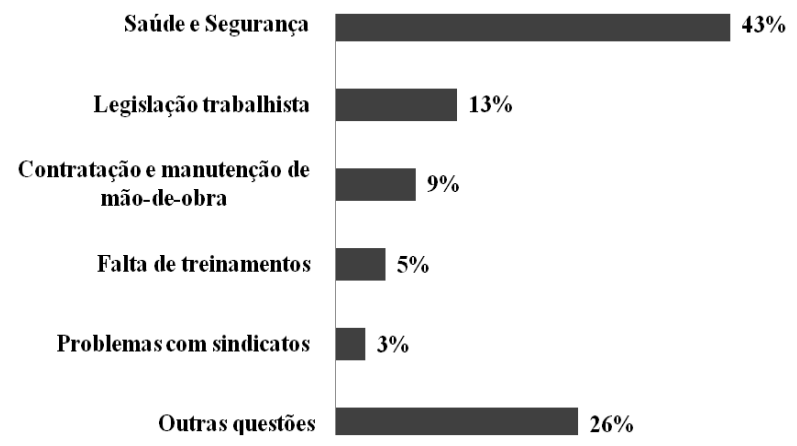

Figura 2 - Percentual de não conformidades referentes ao Princípio 4, nas Unidades de Manejo Florestal certificadas no Estado de Minas Gerais.

Figure 2-Percentage of nonconformities referents to Principle 4 on the Forest Management Units certified in Minas Gerais state.

Revista Árvore, Viçosa-MG, v.36, n.4, p.747-757, 2012 não foram delimitadas e marcadas, não podendo, com isso, dar garantia do cumprimento do que é estabelecido na legislação. Dessa forma, em alguns casos, de acordo com as informações dos relatórios de monitoramento, verificou-se que foi necessária a adequação de plantios de espécies comerciais já estabelecidos aos limites das APP, após o correto mapeamento das propriedades.

Com o mapeamento e marcação das áreas, foi possível a criação de sistemas integrados, em que os encarregados recebem as áreas previamente planificadas e mapeadas, com os limites dos plantios, da infraestrutura e das restrições ambientais, incluindo as APPs. Além disso, é requerido que as operações florestais sejam monitoradas para garantir que a planificação está sendo seguida e, com isso, evitar ocupações indevidas do solo e garantir o cumprimento legal.

A certificação florestal exige a avaliação do estado de conservação das APPs e, caso necessário, a recuperação delas. Verificou-se que em alguns casos foi realizado apenas o acompanhamento de sua regeneração e, em outros, onde a área havia sido ocupada, foi requerido um plano de recuperação com plantio de espécies nativas endêmicas da região.

Com relação às áreas de RL, além de mapeamento e delimitação das áreas em campo, um dos itens faltantes verificados era a sua averbação, uma exigência do Código Florestal. A maior parte das UMF certificadas já possuía as áreas de RL definidas no escopo de suas propriedades, porém não estavam averbadas em sua totalidade no cartório de registro de imóveis do seu município. A averbação das áreas é necessária para garantir sua integridade e não fragmentação, caso a propriedade seja vendida ou passada à herança.

Em alguns casos, devido às extensas áreas de propriedades das empresas, foram apresentados um plano e um cronograma de ação para a averbação dessas áreas. Entende-se também que os processos nos cartórios são demorados, passando, muitas vezes, o prazo de um ano. Assim, o tempo de execução desses planos e cronogramas variou de um a dois anos, dependendo da situação das UMFs.

No período abrangido pelo estudo, todas essas não conformidades foram solucionadas, comprovando a contribuição da certificação para o cumprimento dos requisitos referentes às áreas de RL e APPs. Apesar de serem requerimentos legais, essas questões ainda 
eram pendentes nas organizações florestais, e o processo de certificação foi um catalisador para que elas fossem atendidas em curto prazo, provavelmente menor, se comparado com as organizações não certificadas.

A segunda questão com maior número de não conformidades foi a legislação trabalhista (Figura 1). Porém, o menor número de não conformidades pode ser justificado considerando-se que no padrão FSC os direitos dos trabalhadores e vários aspectos da legislação aplicável também são abordados no Princípio 4.

Nos casos estudados, as questões estavam diretamente relacionadas aos trabalhadores terceirizados, abrangendo temas como regularização de contratos, recolhimento de encargos e remuneração dentro das normas da Consolidação das Leis do Trabalho (CLT).

De acordo com o texto dos padrões do FSC, não é aceitável que a terceirização seja uma forma de flexibilização das relações de trabalho e dos direitos dos trabalhadores. O FSC considera que os princípios e critérios de certificação se aplicam a todos os trabalhadores operando na UMF e preveem que as diferenças de tratamento entre trabalhadores próprios e terceirizados devem ser minimizadas.

Como resultados das ações corretivas para as não conformidades detectadas, as organizações passaram a envolver seus prestadores de serviços, regularizando o trabalho dos terceiros ou substituindo atividades terceirizadas por aquelas desempenhadas por pessoal próprio.

Todas as demais não conformidades verificadas nos outros itens apresentados pela Figura 1 foram devidamente resolvidas pelas organizações e monitoradas nas auditorias subsequentes.

\subsection{Princípio 4 - Relações comunitárias e direito dos trabalhadores}

No Princípio 4, a grande parte das não conformidades foi referente ao não cumprimento de requisitos e Normas de Saúde e Segurança do Trabalho, tanto de trabalhadores próprios quanto de terceiros, como ilustrado na Figura 2.

O Princípio 4 abrange, além dos requisitos legais e normas regulamentadoras do trabalho, os impactos sociais das atividades de manejo e as relações com as comunidades do entorno. Os problemas referentes a essas questões foram inseridos no último item da
Figura 2 (26\%) e, apesar de quantificados, não foram abordados neste trabalho, por não se tratar de questões específicas do âmbito legal.

Em média, cada UMF analisada apresentou mais de 10 não conformidades nesse princípio (como somatória de todas as não conformidades levantadas no período avaliado). O item Saúde e Segurança apresentou $42 \%$ do total de não conformidades (Figura 2), sendo considerado o mais crítico para o grupo estudado entre todos os requerimentos do padrão FSC.

Analisando especificamente o item "Saúde e Segurança", observou-se que nesse item foram agrupados os desvios relacionados com as Normas Regulamentadoras do Trabalho (NRs), as questões referentes aos procedimentos de colheita florestal, aspectos relativos à alimentação dos trabalhadores e de forma geral, toda e qualquer questão que pudesse resultar em danos à saúde e segurança dos trabalhadores (Figura 3).

A NR 31 - "Norma Regulamentadora de Segurança e Saúde no Trabalho na Agricultura, Pecuária, Silvicultura, Exploração Florestal e Aquicultura" é a principal norma de saúde e segurança aplicável ao setor florestal, e o não atendimento de seus requisitos na íntegra foi a principal causa das não conformidades levantadas dentro do tema Saúde e Segurança.

Algumas não conformidades estavam relacionadas à falta de monitoramento das normas de segurança, requerendo que a empresa tivesse meios de garantir que a NR 31 estava sendo cumprida integralmente tanto pelos trabalhadores próprios quanto terceirizados. Outras

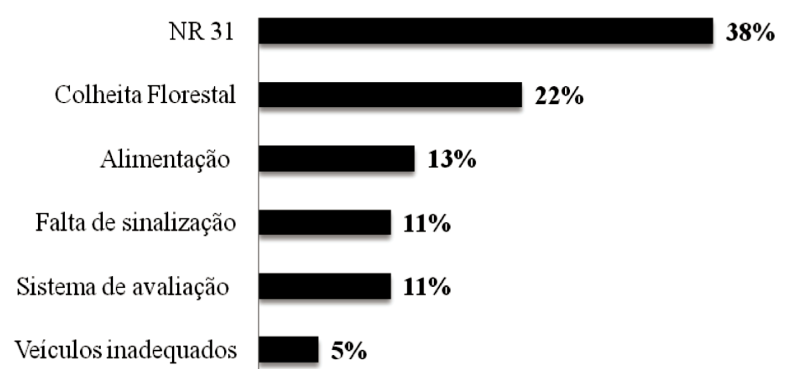

Figura 3 - Percentual de não conformidades referentes à saúde e segurança, nas Unidades de Manejo Florestal certificadas no Estado de Minas Gerais.

Figure 3 - Percentage of nonconformities referent to health and safety on the Forest Management Units certified in Minas Gerais state.

Revista Árvore, Viçosa-MG, v.36, n.4, p.747-757, 2012 
estavam relacionadas a aspectos específicos de operações florestais, como a aplicação de herbicidas e as práticas exigidas por lei para proteção do trabalhador (obrigatoriedade do uso de Equipamento de Proteção Individual (EPI), treinamento, disponibilidade de água para higiene e existência de procedimentos de emergência).

O segundo item de maior ocorrência foi referente a questões da colheita florestal, que é considerada a operação de maior risco do manejo florestal. É fundamental a utilização completa dos equipamentos de segurança e seguir à risca as instruções e a planificação da operação no campo, para evitar possíveis acidentes.

Para solucionar os problemas, as empresas optaram por elaborar e implantar um programa de capacitação dos operadores, do qual foram evidenciados pela certificadora: laudo de vistorias das operações de derrubada e manuseio de árvores; manual de treinamento para operador de motosserra e ajudante de motosserra; cronograma de execuções de treinamentos na colheita; e registros dos treinamentos realizados. Adicionalmente, realizou-se a implantação de melhor sinalização dos locais de colheita, alertando quanto às situações de risco.

Outra não conformidade verificada foi relatada no procedimento de descascamento das toras. Quando o sistema é semimecanizado, necessita-se de outra máquina para realizar tal procedimento. No caso avaliado, essa máquina não oferecia segurança aos trabalhadores, e a empresa foi notificada para que tomasse as devidas providências.

Todas as não conformidades citadas foram solucionadas e são continuamente monitoradas.

Em relação às não conformidades de Saúde e Segurança, a questão da alimentação foi evidenciada em cinco das sete UMF verificadas. Os itens de alimentação são regulamentados pela Resolução 216 da Agência Nacional de Vigilância Sanitária (ANVISA), que dispõe sobre "Regulamento Técnico de Boas Práticas para Serviços de Alimentação". Os principais problemas citados nos relatórios foram a falta de orientação nutricional aos trabalhadores e o acondicionamento térmico da comida até o horário da refeição. Segundo a Resolução 216, a alimentação dos trabalhadores não deve ultrapassar o tempo de $6 \mathrm{~h}$ entre a produção e o consumo e deve ser servida a uma temperatura mímina de $60^{\circ} \mathrm{C}$.
A maior parte dos casos estava relacionado aos trabalhadores terceirizados, que traziam sua própria comida de casa, exedendo o período permitido entre a produção e o consumo, como mencionado. Para resolver essas questões, foi verificado que houve negociação com o sindicato local, a fim de avaliar a distribuição das refeições a todos os trabalhadores que atuavam em sua unidade de manejo florestal, garantindo a qualidade das refeições a todos eles. Também foi relatado que houve parcerias com instituições de ensino superior do Curso de Nutrição, para fornecer treinamento e orientação nutricional a todos os trabalhadores próprios e terceirizados.

Os outros $26 \%$ classificados como "Outras questões" (Figura 2) foram relativas às questões específicas do Padrão FSC. Essas são referentes, principalmente, às questões relacionadas à comunidade e aos impactos sociais causados pelas atividades florestais. Mas, por não se tratar do cumprimento da legislação, essas questões não foram abordadas neste trabalho.

Todas as não conformidades, maiores e menores, identificadas nos casos estudados foram tratadas, porém novamente se destacou que os Planos de Manejo eram verificados anualmente e as partes interessadas, periodicamente consultadas.

Todas as demais não conformidades verificadas nos outros itens apresentados pelas Figuras 2 e 3 foram devidamente resolvidas pelas organizações estudadas, e os relatórios indicaram que os aspectos foram monitorados nas auditorias subsequentes.

\section{DISCUSSÃO}

O maior percentual de não conformidades foi referente ao Princípio 1 (61\%) e, de certa forma, era esperado, devido à dificuldade dos proprietários brasileiros em se adequarem totalmente a essa legislação. Segundo Ahrens (2003), muitos proprietários sabem da existência do Código Florestal brasileiro (instituído em 1965), mas apenas alguns desses conhecem e, mesmo assim, parcialmente o seu conteúdo; e poucos proprietários de terras aceitam-no como instrumento válido e legítimo para a proteção do patrimônio florestal brasileiro.

Outro problema, em Minas Gerais, é a própria geomorfologia do Estado, que resulta em dificuldades para se cumprirem todas as exigências legais ambientais,

Revista Árvore, Viçosa-MG, v.36, n.4, p.747-757, 2012 
já que as leis ambientais não são separadas por região ou, mais especificamente, por formações vegetacionais (por exemplo, cumprimento dos limites das áreas de preservação em encostas e topos de morros).

Segundo o estudo de Jacovine et al. (2008), as áreas de preservação correspondiam, em média, a 43,75\% do total das áreas das propriedades rurais avaliadas na bacia do rio Pomba, MG, confirmando a premissa de que no Estado, em razão da sua topografia e abundância de cursos d'água, grande parte das propriedades tem restrições quanto à sua utilização. Porém, nos casos estudados neste trabalho, tratando-se de grandes organizações florestais, o não cumprimento das leis ambientais pode ter vindo do próprio histórico do setor florestal em Minas Gerais, estabelecido inicialmente com os incentivos fiscais, em que era permitido e autorizado o maior aproveitamento do uso do solo, incluindo as áreas de preservação permanente em situações em que o código florestal proibia e também não se exigia o Estudo de Impacto Ambiental (EIA RIMA), outra ferramenta de importante auxílio na legislação ambiental. Outra questão foi a falta de fiscalização efetiva, após a publicação do Código Florestal, e que a lei existe no papel, mas de fato não é cobrada ou fiscalizada.

Conforme os resultados, os problemas principais no descumprimento da legislação ambiental foi falta de adequação das questões relacionadas às áreas de preservação permanente e reserva legal. Algumas delas não foram cumpridas imediatamente, como relatado, principalmente as que se tratavam da averbação da reserva legal.

A todas essas questões, as organizações apresentaram planos de ação e cronogramas. Devese salientar que esses planos têm prazo a ser cumprido e são monitorados anualmente. Caso a organização certificada não cumpra com os planos de ação acordados, poderá receber uma não conformidade maior e ter seu certificado suspenso ou cancelado.

Segundo Shlyter (2009), a eficácia ambiental em uma organização florestal não depende somente do sistema de certificação adotado e do seu rigor, mas também de como essas práticas ambientais serão aceitas e internalizadas pelos funcionários (próprios ou terceiros), por isso o monitoramento e acompanhamento tornam-se tão importantes e devem ser realizados em conjunto e, paralelamente, às atividades em processo.
Já com relação aos resultados do Princípio 4, as principais não conformidades foram no quesito de Saúde e Segurança do Trabalho, em que grande parte estava relacionada aos trabalhadores terceirizados. Segundo Castral (2003), na relação terceirizada as empresas contratantes repassavam a responsabilidade sobre o cumprimento dos direitos trabalhistas para as empresas contratadas, fato que acarretou consequências perversas na condição de trabalho pelo não cumprimento da legislação. Porém, para a certificação florestal os trabalhadores terceirizados são considerados da mesma maneira que os próprios, isto é, eles devem ter os mesmos direitos e benefícios. De acordo com as normas do FSC, não é aceitável que a terceirização seja uma forma de flexibilização das condições de trabalho e dos direitos dos trabalhadores.

Segundo Araújo (2008), a certificação tem promovido o diálogo entre as diferentes partes interessadas, identificando os interesses individuais e a definição de um manejo florestal abrangente e eficaz, trazendo, dessa forma, uma série de impactos positivos não somente sobre o meio ambiente, mas também entre as organizações e as comunidades.

Outro problema identificado foi nos procedimentos da colheita florestal, em Minas Gerais. O relevo acidentado, muitas vezes, impede o corte mecanizado. Para realizar a derrubada, nesses casos utiliza-se, então, o chamado corte semimecanizado realizado com motosserras. Como a motosserra é manuseada diretamente pelo operador e a parte cortante fica próxima dele, há um grande risco de acidentes.

Para evitar acidentes nesse tipo de área, o treinamento e capacitação dos operadores de motosserra e seus ajudantes são fundamentais, sendo em algumas situações obrigatórios. A análise de risco de cada atividade também é muito importante para identificar os pontos críticos. A empresa deve verificar seus planos de Saúde e Segurança no mínimo a cada 12 meses, verificando-se os pontos de melhoria. Mas, muitas vezes, os acidentes acontecem por falta de cuidado dos trabalhadores.

Segundo Canto (2007), a atribuição dos acidentes à fatalidade é justificada pelo desconhecimento ou conhecimento parcial dos trabalhadores quanto aos riscos inerentes às atividades de colheita florestal, pois se pode afirmar que nenhum acidente ocorre por fatalidade. Os acidentes são causados por atos inseguros, condições inseguras ou os dois fatores em conjunto.

Os problemas com alimentação foram frequentes entre as organizações verificadas, principalmente nas frentes de trabalho de campo. Como relatado, a maior

Revista Árvore, Viçosa-MG, v.36, n.4, p.747-757, 2012 
parte dos trabalhadores trazia a sua comida de casa sem nenhum acompanhamento nutricional ou condições térmicas adequadas. Fica evidente que esse era um problema comum na área florestal e que somente foi resolvido nessas organizações após passarem pelo processo de certificação florestal. Adequar-se a esses quesitos não foi fácil, e cada empresa adotou uma estratégia, mas resolveram os desvios. Algumas empresas investiram para que elas próprias realizassem a distribuição de alimentação em campo, e outras contrataram parecerias com instituições de ensino para a realização de um acompanhamento nutricional e treinamento aos trabalhadores.

Segundo estudo de Castral (2003), realizado em uma das organizações florestais mineiras certificadas, na questão da alimentação houve melhoria significativa após a implantação do processo de certificação, de forma que o trabalhador passou a receber cesta básica e alimentação durante o período de trabalho, realizando as refeições em instalações adequadas.

Castral (2003) concluiu também em seu estudo que as mudanças realizadas para atender à certificação foram importantes para os trabalhadores, tornando-se claro ao ser relatado por eles que se consideravam em situação privilegiada em relação aos trabalhadores das outras organizações florestais, que trabalhavam via empreiteira e não recebiam nenhum benefício.

Em seu estudo, Araújo (2008) também concluiu que a certificação florestal teve efeitos significativos no social, garantindo os direitos trabalhistas e o apoio às comunidades vizinhas. Os resultados de seu estudo indicaram que as organizações certificadas atendiam aos direitos dos trabalhadores e adotavam melhores práticas de segurança.

Entende-se, dessa forma, que a certificação florestal é um mecanismo que efetivamente contribui para a melhoria dos aspectos ambientais e sociais do setor florestal, devendo, assim, ser incentivada por toda a sociedade, seja por meio da preferência por produtos certificados, seja por meio de campanhas favoráveis à sua implementação pelas empresas.

\section{CONCLUSÕES}

- Todas as não conformidades encontradas nos relatórios de certificação das sete unidades de manejo florestal analisadas foram solucionadas, indicando, assim, o cumprimento das questões ambientais e sociais.
- O cumprimento da legislação ambiental, mesmo por organizações estruturadas, ainda é um desafio para as empresas mineiras, mas que está sofrendo avanços com a certificação florestal.

- A evidência dos problemas identificados para o cumprimento das exigências legais relacionadas à área de preservação permanente certamente está relacionada ao relevo montanhoso característico do Estado de Minas Gerais.

- O cumprimento da legislação relacionada à questão social, diante dos vários problemas encontrados, avançou nas organizações certificadas, e isso se torna muito importante, pois os benefícios conseguidos estão contribuindo para a melhoria da vida dos trabalhadores florestais.

- A evidência do alto percentual de não conformidades referentes aos aspectos de Saúde e Segurança nas atividades florestais mostra a necessidade de as empresas florestais melhorarem a integração dos procedimentos com sua efetiva realização em campo pelos operários.

- A certificação é um mecanismo que efetivamente contribui para o cumprimento das questões legais e para a efetivação de melhorias nos aspectos ambientais e sociais da atividade florestal em Minas Gerais.

- Apesar de serem requerimentos legais, verificouse que algumas questões ainda eram pendentes nas organizações florestais e o processo de certificação foi um catalisador para que tais questões fossem atendidas em curto prazo, provavelmente menor, se comparado com as organizações não certificadas.

\section{REFERÊNCIAS}

\section{ASSOCIAÇÃO BRASILEIRA DE PRODUTORES DE FLORESTAS PLANTADAS - ABRAF. Anuário estatístico da ABRAF 2011: ano base 2010. Brasília: 2011. 130p.}

ALVES, R. R. et al. Certificação florestal e o mercado moveleiro nacional. Revista Árvore, v.33, n.3, p.583-589, 2009.

AHRENS, S. O “Novo" Código Florestal Brasileiro: conceitos jurídicos fundamentais. In: CONGRESSO FLORESTAL BRASILEIRO, 8., 2003, São Paulo - SP. Anais... São Paulo SP: 2003. p.1-14. 
ASSOCIAÇÃO MINEIRA DE SILVICULTURA AMS. Negócio florestal. Disponível em www.silviminas.com.br. Acesso em: 15 de dez. de 2011 .

ARAÚJO, M. M. F. C. Forest certification in Brazil: choices and impacts. 2008. 127f. Dissertation (Master of Science in Forestry) University of Toronto, Toronto, 2008.

CANTO, J. L. et al. Avaliação das condições de segurança no trabalho na colheita e transporte florestal em propriedades rurais fomentadas no estado do Espírito Santo. Revista Árvore, v.31, n.3, p.513-520, 2007.

CASTRAL, A. P. Impacto da certificação Florestal nas condições de trabalho no complexo florestal. 2003. 82f. Dissertação (Mestrado em Engenharia de Produção) - Universidade Federal de São Carlos, São Carlos, 2003. 82p.

FOREST STEWARDSHIP COUNCIL - FSC. Global FSC certificates: type and Distribution, January. Disponível em: <http://www.fsc.org/fileadmin/webdata/ public/document_center/powerpoints_graphs/ facts_figures/Global-FSCCertificates-2010-01-15EN.pdf> Acesso em: 15 de fev. de 2010.

GIL, A. C. Métodos e técnicas de pesquisa social. 6.ed. São Paulo: 2008. 200p.

INSTITUTO DE MANEJO E CERTIFICAÇÃO FLORESTAL E AGRÍCOLA - IMAFLORA. 2007. Disponível em: <www.imaflora.org>Acesso em: 15 dez. de 2008.

INSTITUTO NACIONAL DE METROLOGIA, NORMALIZAÇÃO E QUALIDADE INDUSTRIAL INMETRO. ABNT/Cerflor. Empresas certificadas. Disponível em: <http:// www.inmetro.gov.br/qualidade/ cerflor_empresas.asp> Acesso em: 15 jan. de 2010.

JACOVINE, L. A. G. et al. Quantificação das Áreas de Preservação Permanente e de Reserva Legal em propriedades da bacia do Rio Pomba - MG.

Revista Árvore, v.32, n.2, p.269-278, 2008.

NARDELLI, A. M. B.; GRIFFITH, J. J. Modelo teórico para compreensão do ambientalismo empresarial do setor florestal brasileiro. Revista Árvore, v.27, n.6, p.855-859, 2003.

SOCIEDADE BRASILEIRADE SILVICULTURA SBS. Fatos e números do Brasil

florestal. 2008. Disponível em:

<www.sbs.org.br> Acesso em: 03 de abril de 2010.

SCIENTIFIC CERTIFICATION SYSTEM - SCS.

Programa Forest Conservation.

Disponivel em: <www.scscertified.com/forestry/

forest_certclients $>$ Acesso em: 15 de dez. de 2008 .

SOCIETE GENERALEDE SURVEILLANCE-SGS.

Programa SGS Diponivél em:

<www.forestry.sgs.com/forestry_services_index_v2/ mini_site_forestry_certification/

forest_management_reports/qualifor_fmr_brazil.htm> Acesso em:15 de dez. de 2008.

SCHLYTER, P.; STJERNQUIST, I. E.;

BÄCKSTRAND, K. Not seeing the forest for the trees? The environmental effectiveness of Forest certification in Sweden. Forest Policy and Economics, v.11, n.5-6, p.375-382, 2009.

VIEIRA, L. A. N. et al. Dimensionamento do Setor Florestal em Minas Gerais. Revista Cerne, v.12, n.4, p.389-398, 2006. 
